\title{
Distributed Voltage Control Mechanism in Low-Voltage Distribution Grid Field Test
}

\author{
S. Iacovella, K. Lemkens, F. Geth, P. Vingerhoets, \\ G. Deconinck \\ Department of Electrical Engineering \\ KU Leuven, ESAT, Electa/EnergyVille \\ Leuven, Belgium \\ sandro.iacovella@esat.kuleuven.be
}

\author{
R. D'Hulst, K. Vanthournout \\ VITO, Unit Energy Technology/EnergyVille \\ MOL, Belgium \\ reinhilde.dhulst@vito.be
}

\begin{abstract}
In this paper, we present a distributed voltage control mechanism that is being used in the large-scale field-test of the Linear project. The control system developed does not require a communication network between the different households. Only the locally measured household supply voltage is taken into account. The proposed control system is compatible with DSM infrastructure currently being developed, such as home gateways and smart meters. Moreover, the proposed control system can also be used as a fallback mechanism for other communication-based DSM control systems when communication fails or when the system has been compromised due to cyber security issues. Using Monte Carlo simulations on two accurately modeled field test grids and device models, the proposed approach and its various parameter set points are benchmarked against the optimal Dynamic Programming solution. Simulation results point out that on average the amount of over and under voltage occurrences can be lowered by more than $30 \%$.
\end{abstract}

Index Terms - Distribution network, field test, voltage control

\section{INTRODUCTION}

$\mathrm{T}$ he European electricity system is facing significant challenges over the coming years and decades. New and binding targets of $20 \%$ renewable energy production by 2020 and an $80 \%$ reduction of greenhouse gas emission by 2050 have strongly increased the penetration of smaller-scale generation into distribution networks [1]. Simultaneously, total energy consumption is rising each year by several percent. These rates of change will only increase due to the expected electrification of heat production and transport.

Regarding distributed production and the accompanying over voltage problems, many distributed voltage control mechanisms have already been implemented in the inverters of the locally installed Distributed Energy Resources (DERs) [2]. Likewise, the increase in energy consumption might also lead to additional under voltage problems stretching the already problematic feeders to their limits even more.

This work is supported by the Flemish Ministry of Science (Minister I. Lieten) via the project Linear organized by the Institute for Science and Technology (IWT). This research is also funded by a Ph.D. grant of the Institute for the Promotion of Innovation through Science and Technology in Flanders (IWTVlaanderen) for S. Iacovella.

KU Leuven and VITO are partners of Energyville, Dennenstraat 7, 3600 Genk, Belgium.
Uncoordinated charging of electric vehicles, boilers and heat pumps could lead to adverse effects on the power system, especially for low voltage distribution networks currently in use. These effects include excessive voltage drops and overloading of network components. Regulating voltage peaks locally could maintain the grid within the acceptable region according to the European EN50160 standard [3], requiring that the 10-minute mean RMS value of the supply voltage should be within $\pm 10 \%$ of the nominal voltage for $95 \%$ of the time, measured on a weekly base. In order to postpone grid updates, lessons can be learnt from the related literature discussing DER integration measures.

This paper focuses on a voltage stabilizing control mechanism using the readily available flexibility of household devices. This system should be compatible with the current Demand Side Management (DSM) infrastructure (e.g. smart appliances, home gateways and smart meters) and be communication-independent. Therefore, it can also be used as a fallback mechanism when communication fails or when the system has been compromised due to cyber security issues. Regardless of coordination, local decisions based on local voltage measurements are made, while still respecting the comfort demands from the device owner. This bridges the gap between the objectives from the energy consumer, Balancing Responsible Party (BRP) and DSO. The voltage stabilizing mechanism will only be studied as a fallback mechanism in this paper in order to clarify the decisive parameters. Since this algorithm will be deployed in many households during the large-scale field test from the Linear project from mid-2013 until mid-2014 [4], a robust mechanism is envisioned without communication requirements, based on local voltage measurements. Therefore, the concept is to translate grid voltage stabilizing load models, such as developed for PV and EV inverters, to household devices having only discrete switching functionality.

This paper is structured as follows. Section II examines the developed control methodology. Section III discusses the simulation scenario. Section IV presents an overview of simulation results, and finally concluding remarks may be found in Section V. 


\section{DROOP MECHANISM}

In the classical voltage droop method, devices with an invertor-like front-end react instantaneously to grid voltage deviations by changing their power output linearly between a minimum and maximum value. Our proposed droop mechanism aims to bridge the gap between on/off switching of discrete devices and invertor-based power modular droop curves. A specific local arrangement of readily available discrete appliances is updated every fifteen minutes, which is consistent with the control frequency of the majority of existing DSM algorithms, the wholesale energy market timeslots, and most importantly the limitations of the field test hardware.

The main goal of this local control system is to mitigate over and under voltages, defined as voltages with a 10-minute mean RMS value beyond $\pm 10 \%$ of $U_{\text {nom }}$. Since local voltage measurements are only available on a fifteen minute basis, the droop mechanism is unable to perform correcting actions within this shorter timeframe. However, there exists a rather large correlation between the household load of consecutive time steps [5]. Consequently, a relatively large correlation between consecutive household supply voltage measurements is also assumed, advocating the utilization of control actions based on previous time step voltage measurements.

\section{A. Priority based device ordering}

In order to decide which devices to switch on or off, a hierarchical priority-based ordering scheme is used. The priority of a smart appliance is defined as a measure of the urgency to start. When a device almost needs to switch on to preserve the comfort settings of the user, its priority is high. When there still is some time left before it needs to switch on, its priority is low. The device priorities increase linearly to the time of departure or expiration of the flexibility deadline, and are calculated as:

- Electric vehicles and white good appliances:

$$
\operatorname{priority}(t)=100 \frac{t-t_{\text {setup }}}{t_{\text {setup }}-t_{\text {deadline }}}
$$

- Electric hot water boilers:

$$
\operatorname{priority}(t)=100 \frac{\operatorname{SoC}(t)-100}{\operatorname{Soc}_{\min }-100}
$$

with $t$ the current time step, $t_{\text {setup }}$ the time at which the user programs or connects the device, $t_{\text {deadline }}$ the time at which the appliance has to complete its cycle, $\mathrm{SoC}$ the state of charge of the boiler, and $S o C_{\min }$ the minimal allowed state of charge of the boiler. For an electric vehicle, $t_{\text {deadline }}$ equals the expected departure time. In the example given in Fig. 1, the smart appliances are represented by L1 to L4. L1 has a higher priority than L2 and should therefore be switched on at a lower over voltage than L2. On the other side of the graph, L3 has a lower priority than L4, so it can be switched off earlier or delayed first.

\section{B. Dead-band setting}

When a voltage higher than the Upper Droop Limit (UDL) value is measured, the highest priority device is switched on first. When a voltage is measured below the Lower Droop Limit (LDL), the device with the lowest priority is switched off or delayed first. It is important to note that in the pilot, the smart white good appliances are unable to interrupt their running cycle, making a voltage based switch much more critical in case of over voltage than on under voltage. When the measured voltage falls between the Lower and Upper Droop Limits, the smart appliances resort to their default behavior. All devices then start consuming energy after consuming half of their flexibility, equaling a priority of $50 \%$, in order to maximize the potential for compensating under as well as over voltages at the local household level.

\section{Device voltage thresholds}

Based on the average voltage during the previous fifteen minutes, one or more devices are switched according to the hierarchical device ordering scheme. In Fig. 1, each load is represented by two rectangles: a blue rectangle and a grey rectangle, deviating in the manner they intersect with the red invertor-based power modular droop curves. The height of these rectangles represents the power rating of the load. The grey rectangles depict the fixed voltage threshold method, or $P$-method, where the device voltage threshold of the highest (lowest) priority device corresponds with the specified UDL (LDL). Each subsequent available device crosses the droop curve at zero power. The blue rectangles on the other hand intersect with the droop curve halfway their power, meaning the highest (lowest) priority devices will not yet switch on exactly at the UDL (LDL), but somewhat later on. This power-dependent voltage threshold method, or P/2-method, can be used when the P-method causes devices to synchronize their droop actions, by introducing switching randomness along the feeder. The switching delay depends on the height of the power rectangle.

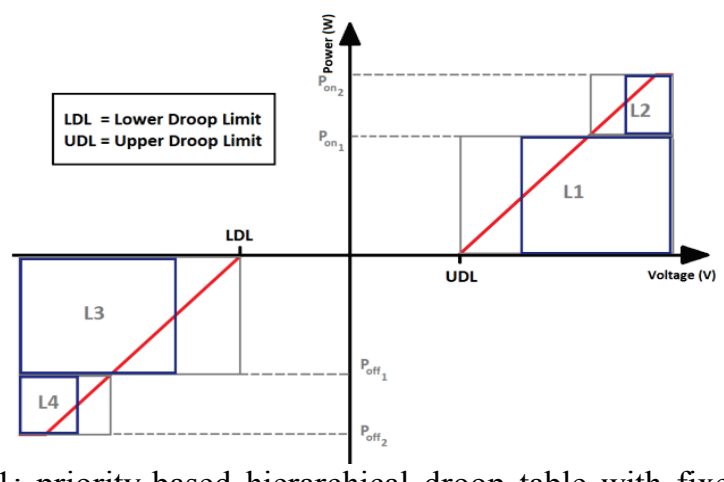

Fig. 1: priority-based hierarchical droop table with fixed (P, grey) and power-dependent $(\mathrm{P} / 2$, blue) voltage thresholds.

\section{SCENARIO}

The necessity of using readily available appliances and infrastructure from the Linear field test influenced the previously discussed design choices in a number of ways. First, all smart appliances that are managed by the control system are appliances that can only be switched on or off. No power modulating device behavior is possible. The smart appliances that are used are white good appliances (dishwasher, washing machine, tumble dryer), electric hot water boilers, and electric vehicles. Secondly, the comfort settings of the user always take priority over control system behavior, a principal requirement within the pilot. In order to 
unambiguously allocate voltage quality gains to our proposed method, Monte Carlo (MC) experiments are conducted for the various parameter settings. The results are then benchmarked against the optimal Dynamic Programming solution, taking into account the three phase voltages and smart appliance information. An overview of all 3000 conducted simulation runs can be found in Fig. 3. Since initial simulation results indicated a higher dependency on local production than on consumption (see section II B), four different summer days were analyzed and only one winter day. The normalized PV profiles for the summer days can be seen in the figure below.

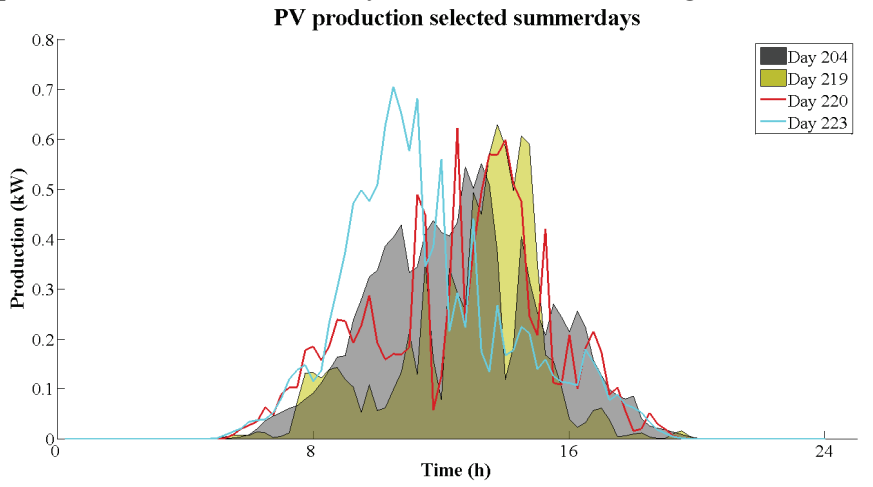

Fig. 2: PV production for the four summer days

These household consumption and production profiles are then applied on two field test feeders, with fifteen and six smart households respectively, where exact smart appliance locations are known. For each simulation day and grid selection fifteen MC simulations are conducted where random smart appliance power profiles and flexibilities are assigned. Each MC run then consists of four simulations: two voltage threshold methods ( $\mathrm{P}$ and $\mathrm{P} / 2)$ using nine different dead-band settings (see Table I), the default behavior and benchmark run.

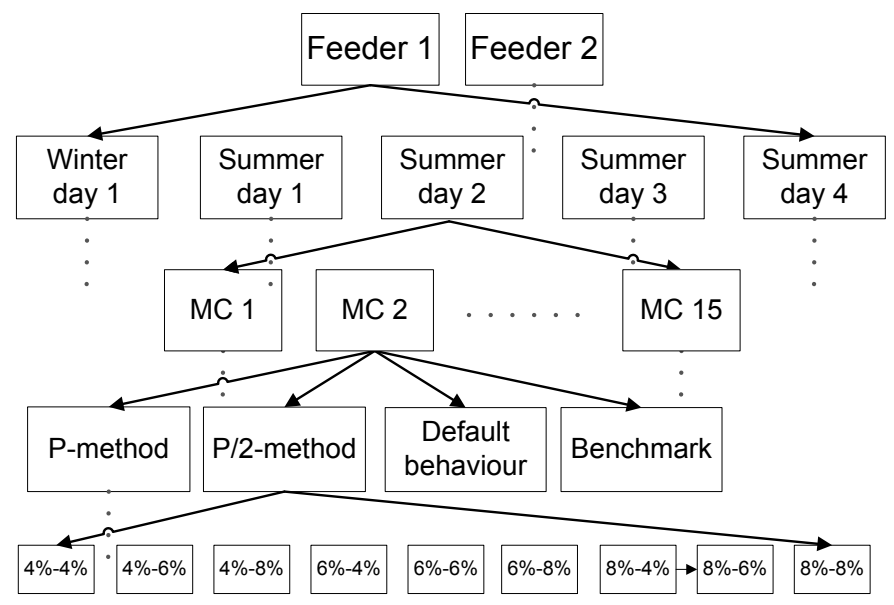

Fig. 3: Monte Carlo simulations overview

Table I: Discrete droop parameters

\begin{tabular}{|c|c|}
\hline Parameter & Value \\
\hline Lower Droop Limit (LDL) & $-4 \%,-6 \%$ or $-8 \%$ of $\mathrm{U}_{\text {nom }}$ \\
\hline Upper Droop Limit(UDL) & $4 \%, 6 \%$ or $8 \%$ of $\mathrm{U}_{\text {nom }}$ \\
\hline Threshold Voltage (VL) & Fixed (P) or power-dependent $(\mathrm{P} / 2)$ \\
\hline
\end{tabular}

\section{A. Grid topology}

The proposed scenario uses two actual feeder topologies in the region of Flanders, Belgium. The feeders have a threephase topology, with both underground and overhead connections. For the static load flow analysis a three-phase backward-forward sweep method is used, taking into account the phase unbalance.

\section{B. PV installations}

The used PV profiles are derived from measurements on one existing installation at the KU Leuven. PV Installations larger than $5.9 \mathrm{kVA}$ are three-phase connected as imposed by regulations.

\section{Household load profiles}

Each simulation, a set of 38 load profiles is selected. The available load profiles are statistically representative for the population in Belgium, and were measured on a $15 \mathrm{~min}$. basis. Smart appliance profiles as well as PV profiles are added to these uncontrollable base load profiles where applicable.

\section{Smart appliances: white goods}

The power profiles of the dishwasher, washing machine and tumble dryer are based on synthetic models of the respective appliances [6]. It is assumed that the users offer a normally distributed appliance flexibility with a mean of four hours and a standard deviation of one hour. In the pilot, the smart white good appliances are unable to interrupt their program once started.

\section{E. Electric vehicles}

A total of 4 single-phase connected electric vehicles are randomly distributed over the smart households. Their battery SoC, arrival and departure times are based on an availability study given in [7]. The discrete charging power and battery capacity are based on the specifications of the Renault Fluence, which is used in the pilot. The charging of the electric vehicle can be interrupted at any discrete time step of fifteen minutes.

\section{F. Electric hot water boiler}

The electric hot water boiler is modeled according to [8]. The boiler parameters are those of a Siemens DF2017 as this is the boiler deployed in the pilot. The boilers in the pilot are able to switch fully on or off at any instant, provided that the State of Charge $(\mathrm{SoC})$ does not fall below the minimal allowed SoC, or exceeds a SoC of $100 \%$.

\section{Simulation RESUlTS}

The effectives of the algorithm in mitigating voltage issues is measured by analyzing the percentage gain in number of under and over voltage issues with respect to the uncontrolled default behavior. A voltage issue corresponds with a measured supply voltage at the smart household beyond $U_{\text {nom }} \pm 10 \%$. First, Fig. 4 and Table III show the number of under voltage issues during all MC runs and simulations days, for the benchmark, uncontrolled and controlled $\mathrm{P}$ and $\mathrm{P} / 2$ methods. It can be seen that a narrow lower droop limit (4\%) leads to less under voltage issues and the lowest standard deviation (SD). 


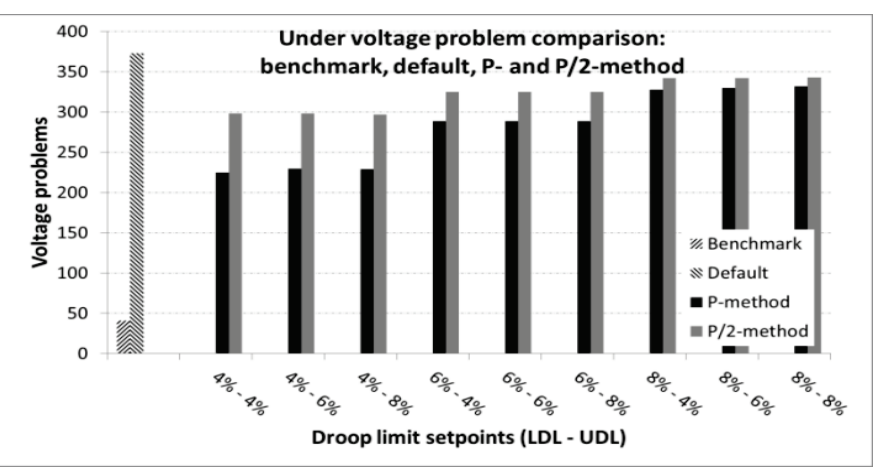

Fig. 4: Number of under voltage issues on feeder 1

Table III: Under voltage problem comparison for feeder 1

\begin{tabular}{|l|c|c|c|c|c|c|c|c|c|}
\hline \multirow{2}{*}{$\begin{array}{l}\text { LDL- } \\
\text { UDL }\end{array}$} & \multicolumn{10}{|c|}{ P method } \\
\cline { 2 - 10 } & $\mathbf{4 \%}$ & $\begin{array}{c}\mathbf{4 \% -} \\
\mathbf{6 \%}\end{array}$ & $\begin{array}{c}\mathbf{4 \% -} \\
\mathbf{8 \%}\end{array}$ & $\begin{array}{c}6 \% \\
4 \%\end{array}$ & $\begin{array}{c}6 \%- \\
6 \%\end{array}$ & $\begin{array}{c}6 \%- \\
8 \%\end{array}$ & $\begin{array}{c}8 \%- \\
4 \%\end{array}$ & $\begin{array}{c}8 \%- \\
6 \%\end{array}$ & $\begin{array}{c}8 \%- \\
8 \%\end{array}$ \\
\hline Total & $\mathbf{2 2 5}$ & $\mathbf{2 3 0}$ & $\mathbf{2 2 9}$ & 289 & 289 & 289 & 332 & 328 & 330 \\
\hline SD & $\mathbf{4 . 3 0}$ & $\mathbf{4 . 3 0}$ & $\mathbf{4 . 3 0}$ & 4.88 & 4.83 & 4.91 & 5.37 & 5.33 & 5.35 \\
\hline Gain(\%) & $\mathbf{3 9 . 7}$ & $\mathbf{3 8 . 3}$ & $\mathbf{3 8 . 6}$ & 22.5 & 22.5 & 22.5 & 12.1 & 11.5 & 11.0 \\
\hline LDL- & \multicolumn{10}{|c|}{ P/2 method } \\
\cline { 2 - 10 } UDL & $\mathbf{4 \% -}$ & $\mathbf{4 \% -}$ & $\mathbf{4 \% -}$ & $6 \%-$ & $6 \%-$ & $6 \%-$ & $8 \%-$ & $8 \%-$ & $8 \%-$ \\
& $\mathbf{4 \%}$ & $\mathbf{6 \%}$ & $\mathbf{8 \%}$ & $4 \%$ & $6 \%$ & $8 \%$ & $4 \%$ & $6 \%$ & $8 \%$ \\
\hline Total & $\mathbf{2 9 8}$ & $\mathbf{2 9 8}$ & $\mathbf{2 9 7}$ & 325 & 325 & 325 & 343 & 342 & 342 \\
\hline SD & $\mathbf{5 . 2 0}$ & $\mathbf{5 . 2 0}$ & $\mathbf{5 . 2 1}$ & 5.25 & 5.25 & 5.26 & 5.54 & 5.54 & 5.52 \\
\hline Gain(\%) & $\mathbf{2 0 . 1}$ & $\mathbf{2 0 . 1}$ & $\mathbf{2 0 . 4}$ & 12.9 & 12.9 & 12.9 & 8.3 & 8.3 & 8.0 \\
\hline
\end{tabular}

Secondly, Fig. 5 and Table IV depict the number of over voltage issues for all scenario's. Note the P-method's weak performance for all dead-band settings with an upper droop limit of $4 \%$. This can be explained by the fact that valuable

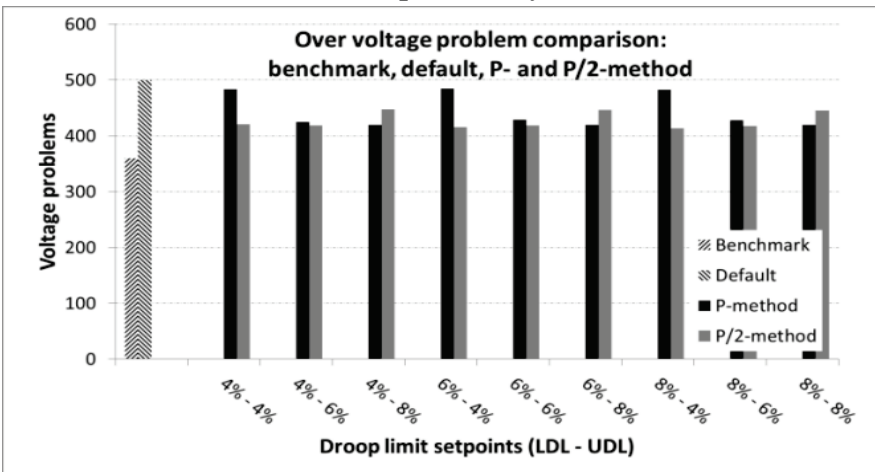

Fig. 5: Number of over voltage issues on feeder 1

Table IV: Over voltage problem comparison for feeder 1

\begin{tabular}{|c|c|c|c|c|c|c|c|c|c|}
\hline \multirow{2}{*}{$\begin{array}{l}\text { LDL- } \\
\text { UDL }\end{array}$} & \multicolumn{9}{|c|}{ P method } \\
\hline & $\begin{array}{c}4 \%- \\
4 \%\end{array}$ & $\begin{array}{c}4 \%- \\
6 \%\end{array}$ & $\begin{array}{c}4 \%- \\
8 \%\end{array}$ & $\begin{array}{l}6 \%- \\
4 \%\end{array}$ & $\begin{array}{c}6 \%- \\
6 \%\end{array}$ & $\begin{array}{c}6 \%- \\
8 \%\end{array}$ & $\begin{array}{c}8 \%- \\
4 \%\end{array}$ & $\begin{array}{c}8 \%- \\
6 \%\end{array}$ & $\begin{array}{c}8 \%- \\
8 \%\end{array}$ \\
\hline Total & 483 & 425 & 420 & 484 & 429 & 420 & 482 & 428 & 420 \\
\hline SD & 9.37 & 9.06 & 8.51 & 9.37 & 9.05 & 8.46 & 9.37 & 9.06 & 8.51 \\
\hline Gain(\% & 3.4 & 15 & 16 & 3.2 & 14.2 & 16 & 3.6 & 14.4 & 16 \\
\hline \multirow{2}{*}{$\begin{array}{l}\text { LDL- } \\
\text { UDL }\end{array}$} & \multicolumn{9}{|c|}{$\mathrm{P} / 2$ method } \\
\hline & $\begin{array}{c}4 \%- \\
4 \%\end{array}$ & $\begin{array}{l}4 \%- \\
6 \%\end{array}$ & $\begin{array}{l}4 \%- \\
8 \%\end{array}$ & $\begin{array}{l}6 \%- \\
4 \%\end{array}$ & $\begin{array}{c}6 \%- \\
6 \%\end{array}$ & $\begin{array}{l}6 \%- \\
8 \%\end{array}$ & $\begin{array}{c}8 \%- \\
4 \%\end{array}$ & $\begin{array}{l}8 \%- \\
6 \%\end{array}$ & $\begin{array}{l}8 \%- \\
8 \%\end{array}$ \\
\hline Total & 421 & 419 & 447 & 416 & 419 & 446 & 414 & 418 & 445 \\
\hline SD & 8.81 & 8.48 & 8.58 & 8.82 & 8.50 & 8.58 & 8.83 & 8.49 & 8.57 \\
\hline Gain(\%) & 15.8 & 16.2 & 10.6 & 16.8 & 16.2 & 10.8 & 17.2 & 16.4 & 11 \\
\hline
\end{tabular}

flexibility is consumed too early, before the actual over voltage problem arises. The entire white good power cycle is also entirely consumed based on one control action. This problem is less pronounced for the $\mathrm{P} / 2$-method, which exhibits randomization along the feeder and an inherent wider deadband region.

Finally, Fig. 6 and Table V show the optimal dead-band setting and droop table ordering method for the combined objective of mitigating the total number of voltage issues. Note that the amount of over voltage issues has been scaled in order not to tune the droop controller excessively on summer days. The settings from Table $\mathrm{V}$ highlighted in bold thus represent the optimal settings for one representative winter and (averaged) summer day. It can be seen that a lower droop limit of $4 \%$ for both methods is critical when aspiring the best performance based on one unique setting for the entire year. The biggest gain in terms of percentage can be made with the P method, using a dead-band of $4 \%-8 \%$.

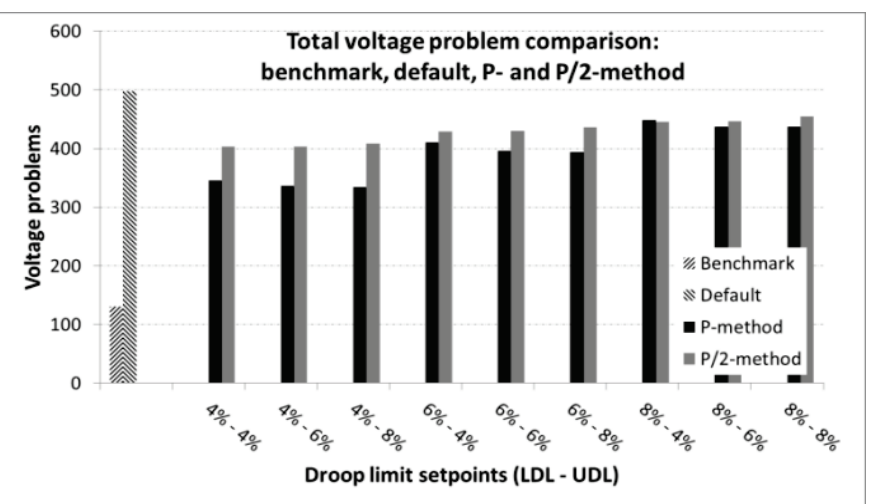

Fig. 6: Total number of voltage issues on feeder 1

Table V: Total voltage problem comparison for feeder 1

\begin{tabular}{|l|c|c|c|c|c|c|c|c|c|}
\hline \multirow{2}{*}{ LDL- } & \multicolumn{10}{|c|}{ UDL } & $\begin{array}{c}\mathbf{4 \% -} \\
\mathbf{4} \%\end{array}$ & $\begin{array}{c}\mathbf{6 \%} \\
\mathbf{6 \%}\end{array}$ & $\begin{array}{c}\mathbf{4 \% -} \\
\mathbf{8 \%}\end{array}$ & $\begin{array}{c}6 \%- \\
4 \%\end{array}$ & $\begin{array}{c}6 \%- \\
6 \%\end{array}$ & $\begin{array}{c}6 \%- \\
8 \%\end{array}$ & $\begin{array}{c}8 \%- \\
4 \%\end{array}$ & $\begin{array}{c}8 \%- \\
6 \%\end{array}$ & $\begin{array}{c}8 \%- \\
8 \%\end{array}$ \\
\hline Total & $\mathbf{3 4 6}$ & $\mathbf{3 3 6}$ & $\mathbf{3 3 4}$ & 410 & 396 & 394 & 449 & 437 & 437 \\
\hline Gain(\%) & $\mathbf{3 0 . 6}$ & $\mathbf{3 2 . 5}$ & $\mathbf{3 2 . 9}$ & 17.7 & 20.4 & 20.9 & 9.9 & 12.2 & 12.2 \\
\hline LDL- & \multicolumn{10}{|c|}{$\mathrm{P} / 2$ method } \\
\cline { 2 - 11 } UDL & $\mathbf{4 \% -}$ & $\mathbf{4 \% -}$ & $\mathbf{4 \% -}$ & $6 \%-$ & $6 \%-$ & $6 \%-$ & $8 \%-$ & $8 \%-$ & $8 \%-$ \\
& $\mathbf{4 \%}$ & $\mathbf{6 \%}$ & $\mathbf{8 \%}$ & $4 \%$ & $6 \%$ & $8 \%$ & $4 \%$ & $6 \%$ & $8 \%$ \\
\hline Total & $\mathbf{4 0 3}$ & $\mathbf{4 0 3}$ & $\mathbf{4 0 9}$ & 429 & 430 & 437 & 446 & 447 & 454 \\
\hline Gain(\%) & $\mathbf{1 9 . 0}$ & $\mathbf{1 9 . 0}$ & $\mathbf{1 7 . 9}$ & 13.9 & 13.7 & 12.3 & 10.5 & 10.3 & 8.8 \\
\hline
\end{tabular}

However, when choosing between both methods, the appliance flexibility consumption should also be taken into account as can be seen in Fig. 7. The superior performance of the P-method can again be observed. However, in terms of dead-band setting sensitivity and ratio of appliance flexibility consumption per voltage problem decrease, the $\mathrm{P} / 2$-method prevails. Depending on the adjustability and cost of flexibility, this method could be preferred. 


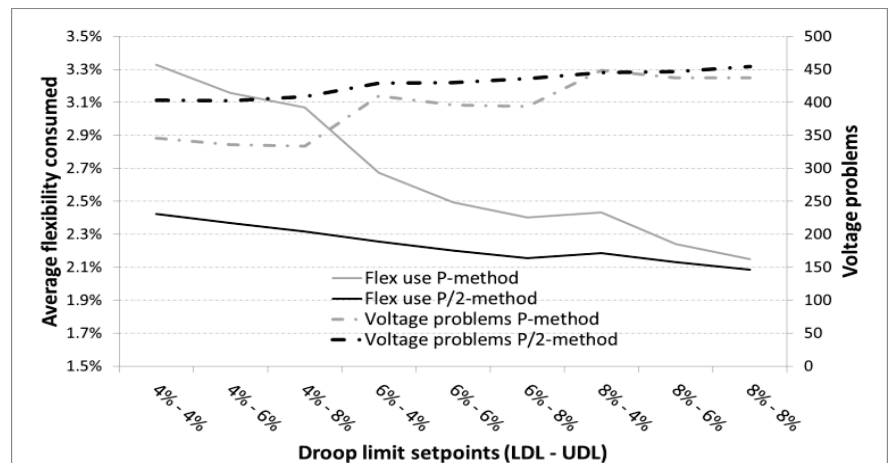

Fig. 7: Trade-off between flexibility usage and number of mitigated voltage problems

Finally the total number of voltage problems on feeder 2 is analyzed for all methods. Since all smart households are located in the first half of the feeder, no voltage problems are measured at those specific locations. However, when taking the voltage at every household into account, positive gains can be noted as shown in Fig. 8. Both methods show similar optimal set-points as before, but since primarily voltage issues at the end of the feeder need to be accounted for by smart households at the beginning of the feeder, a low UDL voltage is required.

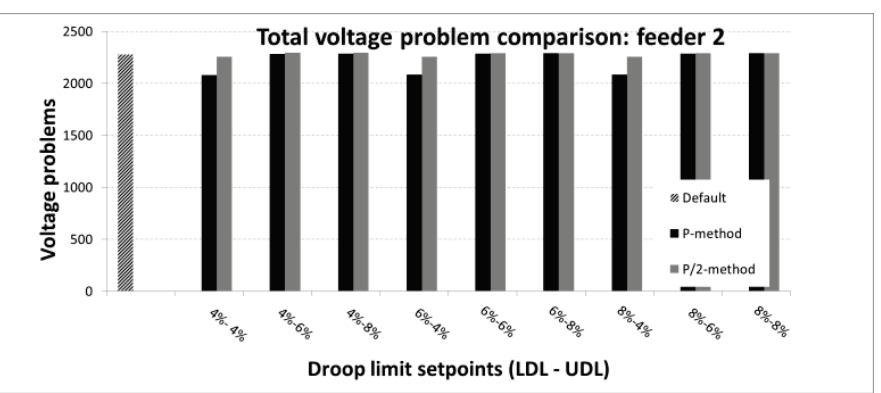

Fig. 8: Total number of voltage issues on feeder 2

Table VI: Total voltage problem comparison for feeder 2

\begin{tabular}{|c|c|c|c|c|c|c|c|c|c|}
\hline \multirow{2}{*}{$\begin{array}{l}\text { LDL- } \\
\text { UDL }\end{array}$} & \multicolumn{9}{|c|}{ P method } \\
\hline & $\begin{array}{c}4 \%- \\
4 \%\end{array}$ & $\begin{array}{r}4 \%- \\
6 \%\end{array}$ & $\begin{array}{c}4 \%- \\
8 \%\end{array}$ & $\begin{array}{l}6 \%- \\
4 \%\end{array}$ & $\begin{array}{c}6 \%- \\
6 \%\end{array}$ & $\begin{array}{c}6 \%- \\
8 \%\end{array}$ & $\begin{array}{c}8 \%- \\
4 \%\end{array}$ & $\begin{array}{c}8 \%- \\
6 \%\end{array}$ & $\begin{array}{l}8 \%- \\
8 \%\end{array}$ \\
\hline Total & 2077 & 2282 & 2284 & 2083 & 2285 & 2290 & 2083 & 2286 & 2291 \\
\hline $\begin{array}{l}\text { Gain } \\
\text { (\%) }\end{array}$ & 8.9 & 0.0 & -0.1 & 8.7 & -0.2 & -0.4 & 8.7 & -0.2 & -0.4 \\
\hline LDL- & \multicolumn{9}{|c|}{$\mathrm{P} / 2$ method } \\
\hline UDL & $\begin{array}{c}4 \%- \\
4 \%\end{array}$ & $\begin{array}{c}4 \%- \\
6 \%\end{array}$ & $\begin{array}{l}4 \%- \\
8 \%\end{array}$ & $\begin{array}{c}6 \%- \\
4 \%\end{array}$ & $\begin{array}{l}6 \%- \\
6 \%\end{array}$ & $\begin{array}{c}6 \%- \\
8 \%\end{array}$ & $\begin{array}{c}8 \%- \\
4 \%\end{array}$ & $\begin{array}{c}8 \%- \\
6 \%\end{array}$ & $\begin{array}{l}8 \%- \\
8 \%\end{array}$ \\
\hline Total & 2257 & 2292 & 2292 & 2257 & 2291 & 2291 & 2257 & 2291 & 2291 \\
\hline $\begin{array}{l}\text { Gain } \\
\text { (\%) }\end{array}$ & 1.1 & -0.5 & -0.5 & 1.1 & -0.4 & -0.4 & 1.1 & -0.4 & -0.4 \\
\hline
\end{tabular}

\section{V.CONCLUSIONS}

A voltage stabilizing control mechanism using the available flexibility of smart devices within one household is developed. The main advantage of the developed control system is that it does not require a communication network between the different households. Only the locally measured household supply voltage is taken into account. The control system is being rolled out in a real life pilot, requiring the control system to work with smart on/off devices only.
The effect of the developed control system has been simulated on two existing LV distribution feeders, taking into account actual smart appliance presence. Simulation results point out that the amount of over and under voltage occurrences on average are lowered by more than $30 \%$ when using the fixed power method and by almost $20 \%$ when using the power dependent method. This decrease in terms of efficiency is compensated by a lower sensitivity to the dead-band settings and a decrease in flexibility consumption.

Due to the fact that measurement and control actions are only possible on a fifteen minute basis, and the absence of communication, positive gains in number of voltage issues can not be guaranteed, as shown in the analysis for the second feeder. It is also shown that the optimal dead-band setting is dependent on the availability of flexibility, time of year, and voltage problem region.

\section{REFERENCES}

[1] P. Djapic, C. Ramsay, D. Pudjianto, G. Strbac, J. Mutale, N. Jenkins and R. Allan, "Taking an active approach," Power and Energy Magazine, IEEE, vol. 5, no. 4, pp. 68 $77,2007$.

[2] M. Braun, T. Stetz, R. Bründlinger, C. Mayr, K. Ogimoto, H. Hatta, H. Kobayash, B. Kroposki, B. Mather, M. Coddington, K. Lynn, G. Graditi, A. Woyte and a. I. MacGill, "Is the distribution grid ready to accept large-scale photovoltaic deployment? State of the art, progress, and future prospects," in Progress in Photovoltaics: Research and Applications, 26th EU PVSEC, Hamburg, Germany, 2011.

[3] H. Markiewicz and A. Klajn, "Standard EN 50160 Voltage Characteristics in Public Distribution Systems," 2004.

[4] B. Dupont, P. Vingerhoets, P. Tant, K. Vanthournout, W. Cardinaels, T. De Rybel, E. Peeters,. R. Belmans, "LINEAR breakthrough project: Large-scale implementation of smart grid technologies in distribution grids" in Innovative Smart Grid Technologies (ISGT Europe), 2012 3rd IEEE PES International Conference and Exhibition on, 2012, pp. 1-8.

[5] W. Labeeuw, G. Deconinck, "Customer sampling in a smart grid pilot" Power and Energy Society General Meeting, 2012 IEEE, 2012, pp. 1-7.

[6] W. Labeeuw, G. Deconinck, "Non-intrusive detection of high power appliances in metered data and privacy issues", in: EEDAL 2011 - The $6^{\text {th }}$ International Conference on Energy Efficiency in Domestic Appliances and Lighting.

[7] J. Van Roy, N. Leemput, S. De Breucker, F. Geth, P. Tant and J. Driesen, "An Availablilty Analysis and Energy Consumption Model for a Flemish Fleet of Electric Vehicles," European Electric Vehicle Congress (EEVC), pp. 1-12, 2011.

[8] K. Vanthournout, R. D'hulst, D. Geysen and G. Jacobs, "A Smart Domestic Hot Water Buffer," IEEE Transactions on Smart Grid, pp. 2121-2127, 2012 